\title{
Resveratrol suppresses proliferation and induces apoptosis of uterine sarcoma cells by inhibiting the Wnt signaling pathway
}

\author{
AYUKA MINEDA, MASATO NISHIMURA, TOMOHIRO KAGAWA, ERI TAKIGUCHI, \\ TAKAKO KAWAKITA, AKIKO ABE and MINORU IRAHARA \\ Department of Obstetrics and Gynecology, Institute of Biomedical Sciences, \\ Tokushima University Graduate School, Tokushima 770-8503, Japan
}

Received October 15, 2018; Accepted December 13, 2018

DOI: 10.3892/etm.2019.7209

\begin{abstract}
Resveratrol, a natural product and peroxisome proliferator-activated receptor (PPAR) agonist, has been reported to exert anti-cancer effects in several tumor models. A previous study by our group reported that prostaglandin J2, a PPAR $\gamma$ ligand, inhibited cell proliferation in a uterine sarcoma cell line. The aim of the present study was to investigate the role of the Wnt signaling pathway in resveratrol-induced apoptosis and inhibition of cell proliferation in the MES-SA human uterine sarcoma cell line. A WST-1 assay demonstrated that resveratrol inhibited cell proliferation in the MES-SA cell line, and flow cytometry revealed that the number of apoptotic cells increased in a resveratrol dose-dependent manner. The mechanisms underlying these effects of resveratrol were speculated to involve the expression of $\beta$-catenin and its target gene, c-myc, which were examined using western blot analysis. The results revealed a dose-dependent downregulation of this $\beta$-catenin and c-myc. This effect was blunted by a pharmacological inhibitor of glycogen synthase kinase $3 \beta$. Therefore, it is likely that resveratrol inhibited the cell proliferation and increased the number of apoptotic cells, at least partially, via the Wnt signaling pathway. The present results suggest that resveratrol is a potential candidate for the treatment of uterine sarcoma.
\end{abstract}

\section{Introduction}

Among gynecological tumors, uterine sarcoma has one of the poorest prognoses, and the most effective treatment is complete resection. At present, no effective therapeutic drugs are available for cases of recurrent and advanced-stage uterine sarcoma. In recent years, pazopanib and trabectedin have been used to

Correspondence to: Dr Ayuka Mineda, Department of Obstetrics and Gynecology, Institute of Biomedical Sciences, Tokushima University Graduate School, 18-15, Kuramoto, Tokushima 770-8503, Japan

E-mail: mineda.ayuka@tokushima-u.ac.jp

Key words: resveratrol, uterine sarcoma, Wnt signaling pathway, $\beta$-catenin, glycogen synthase kinase- $3 \beta$ treat soft tissue sarcoma containing uterine sarcoma; however, their effects are limited. Thus, novel drugs are urgently required for the treatment of uterine sarcoma.

Trans-3,4',5-trihydroxystilbene (resveratrol) is a natural polyphenolic phytoalexin present in grape skin. It has been reported to function as an agonist of PPAR $\gamma$ (1). In 1997, Jang et al (2) reported on the anti-cancer effects of resveratrol. Previous studies on resveratrol demonstrated that it inhibits the proliferation and induces apoptosis in different cancer cell types, including breast, prostate, stomach, colon, pancreatic and thyroid cancers (3). Resveratrol has potential as a novel drug with minimal side effects. A previous study by our group reported that PGJ2, a PPAR $\gamma$ ligand, inhibited cell proliferation in a uterine sarcoma cell line (4). Resveratrol, which also acts as a PPAR $\gamma$ agonist, has potential as an agent in the chemoprevention of uterine sarcoma.

The canonical Wnt signaling pathway is important in embryonic development. The activation of the Wnt signaling pathway is involved in the onset of certain carcinomas, including colon cancer (5). The Wnt protein induces the accumulation of $\beta$-catenin in the cytoplasm, which then translocates to the nucleus and causes the transcriptional activation of the target genes c-myc and cyclin D (6). Previous studies reported that resveratrol inhibited Wnt signaling via the $\beta$-catenin pathway in osteosarcoma, gastric cancer and colon cancer (7-10). However, the efficacy of resveratrol in human uterine sarcoma and the underlying mechanisms of action have remained elusive. At present, no drugs are available that target the Wnt signaling pathway; however, since this pathway is associated with various cancer types, it may be regarded as an attractive target for novel treatments (11). Resveratrol has potential as a novel therapeutic agent that targets the Wnt signaling pathway.

In the present study, the effect of resveratrol to inhibit the proliferation of uterine sarcoma cells and on the Wnt signaling pathway were examined.

\section{Materials and methods}

Cell line and culture. The MES-SA human uterine sarcoma cell line (European Collection of Cell Cultures, Salisbury, UK) was cultured in McCoy's 5A medium (Wako Pure Chemical Industries, Ltd., Osaka, Japan) with $10 \%$ fetal bovine serum, 
penicillin $(100 \mathrm{U} / \mathrm{ml})$ and streptomycin $(100 \mu \mathrm{g} / \mathrm{ml})$ in an incubator at $37^{\circ} \mathrm{C}$ with air containing $5 \% \mathrm{CO}_{2}$.

Drugs and reagents. Resveratrol was purchased from Tokyo Chemical Industry (Tokyo, Japan). The glycogen synthase kinase (GSK)-3 $\beta$ inhibitor CHIR99021 was purchased from Cayman Chemical (Ann Arbor, MI, USA). The primary antibodies for western blot analysis were $\beta$-catenin (cat. no. 8480), c-myc (cat. no. 13987) and $\beta$-actin (cat. no. 4967), and the secondary antibody was a horseradish peroxidase-conjugated anti-rabbit antibody (cat. no. 7074). All were purchased from Cell Signaling Technology, Inc. (Danvers, MA, USA).

WST-1 cell proliferation assay to. Cells were seeded on a 96-well microplate at a density of $2 \times 10^{3}$ cells/well in $100 \mu 1$ culture medium and incubated for $24 \mathrm{~h}$. The cells were then treated with different concentrations of resveratrol $(0,10,20$ and $40 \mu \mathrm{g} / \mathrm{ml})$ for 24,48 or $72 \mathrm{~h}$. WST-1 reagent $(10 \mu \mathrm{l})$ was added to each well, and the cells were incubated at $37^{\circ} \mathrm{C}$ for $1 \mathrm{~h}$. The absorbance was measured at $450 \mathrm{~nm}$ using a microplate reader (Thermo Scientific Varioskan Flash Multimode reader; Thermo Fisher Scientific, Inc., Waltham, MA, USA). At least 6 wells were used for each concentration of the tested reagent.

Analysis of cell apoptosis by flow cytometry. The Annexin V/fluorescein isothiocyanate (FITC) apoptosis detection kit (cat. no. 2375; Beckman Coulter, Inc., Brea, CA, USA) was used to detect cell apoptosis. Samples were washed with cold PBS twice and centrifuged at $500 \mathrm{xg}$ at $4^{\circ} \mathrm{C}$ for $3 \mathrm{~min}$. The cell density was adjusted to $5 \times 10^{5}$ cells $/ \mathrm{ml}$ in binding buffer. A $100-\mu 1$ aliquot of the cell suspension was mixed with $5 \mu$ l Annexin V-FITC prior to incubation in the dark on ice for $15 \mathrm{~min}$. The suspension was then mixed with $2.5 \mu \mathrm{l}$ propidium iodide on ice. Samples were examined using a flow cytometer (BD FACSVers; BD Biosciences, Franklin Lakes, NJ, USA).

Western blot analysis. Cells were cultured to $80 \%$ confluence in $60-\mathrm{mm}$ dish. The cells were then treated with different concentrations of resveratrol $(0,10,20$ and $40 \mu \mathrm{g} / \mathrm{ml})$ for $72 \mathrm{~h}$ at $37^{\circ} \mathrm{C}$. A group was prepared with resveratrol alone and fixed with $10 \mathrm{ng} / \mathrm{ml}$ GSK3 $\beta$ inhibitor (CHIR99021) at each resveratrol concentration $(10,20,40 \mu \mathrm{g} / \mathrm{ml})$ for $72 \mathrm{~h}$ at $37^{\circ} \mathrm{C}$. The cells were lysed in M-PER Mammalian Protein Extration reagent (Thermo Fisher Scientific, Inc.). Protein concentrations were determined using a Pierce BCA Protein Assay kit (Thermo Fisher Scientific, Inc.). Protein samples $(20 \mu \mathrm{g})$ were separated by $7.5 \%$ SDS-PAGE gels (TGX precast gel; Bio-Rad Laboratories, Hercules, CA, USA) and transferred to a polyvinylidene difluoride membrane. The membrane was blocked with $3 \%$ bovine serum albumin in Tris-buffered saline with $0.1 \%$ Tween-20 at room temperature for $1 \mathrm{~h}$ and was treated with primary antibodies $(1: 1,000)$ overnight at $4^{\circ} \mathrm{C}$, followed by secondary antibodies $(1: 2,000)$ for $1 \mathrm{~h}$ at room temperature. The signal was detected using an ECL Plus system (GE Healthcare, Little Chalfont, UK). Band intensities were quantified using ImageJ software version 1.51 (National Institutes of Health, Bethesda, MA, USA).

Statistical analysis. Statistical analysis were performed using Ekuseru-Toukei 2012, version 1.16 (Social Survey Research

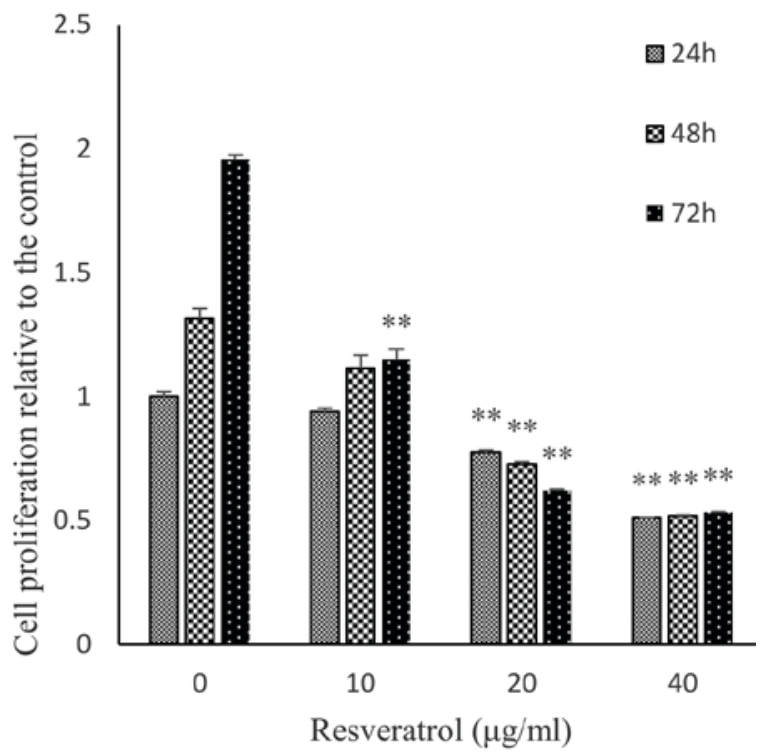

Figure 1. Effects of resveratrol on the proliferation of the human MES-SA uterine sarcoma cell line. MES-SA cells were treated with resveratrol at 0 , 10,20 or $40 \mu \mathrm{g} / \mathrm{ml}$ for 24,48 or $72 \mathrm{~h}$, and the resulting number of viable cells was determined using the WST-1 assay. The absorbance is expressed as the mean \pm standard error of the mean $(n=6) .{ }^{* *} \mathrm{P}<0.01$ vs. the control.

Information Co., Ltd., Tokyo, Japan). Values are expressed as the mean \pm SEM. The significance of differences in the experimental and control groups was assessed using Dunnett's test. $\mathrm{P}<0.05$ was considered to indicate a statistically significant difference.

\section{Results}

Resveratrol inhibits the proliferation of MES-SA cells. The WST-1 assay was performed to determine the proliferation rate of human MES-SA cells treated with resveratrol. MES-SA cells were treated with $0,10,20$ and $40 \mu \mathrm{g} / \mathrm{ml}$ resveratrol for 24,48 or $72 \mathrm{~h}$. The inhibitory rates of uterine sarcoma cell proliferation were $61 \%$ at $40 \mu \mathrm{g} / \mathrm{ml}$ resveratrol, $45 \%$ at $20 \mu \mathrm{g} / \mathrm{ml} \mathrm{resveratrol} \mathrm{at}$ $48 \mathrm{~h}$. The cell proliferation was suppressed in a concentrationand time-dependent manner with $\geq 20 \mu \mathrm{g} / \mathrm{ml}$ resveratrol for $24 \mathrm{~h}$ or longer (Fig. 1).

Resveratrol induces apoptosis of MES-SA cells. Apoptotic changes in human MES-SA cells treated with resveratrol were assessed by flow cytometry. The results revealed that after $72 \mathrm{~h}$ of incubation with resveratrol at various concentrations, the apoptotic rate was increased in a dose-dependent manner. The apoptotic rate was $36.2 \%$ in the cells treated with $40 \mu \mathrm{g} / \mathrm{ml}$ resveratrol and 3.8 and $10.6 \%$ in those treated with 10 and $20 \mu \mathrm{g} / \mathrm{ml}$ resveratrol, respectively (Fig. 2).

Resveratrol inhibits Wnt signaling in MES-SA cells. Cells were treated with resveratrol or a combination of resveratrol and CHIR99021, a GSK3 $\beta$ inhibitor, at several concentrations for $48 \mathrm{~h}$. Western blot analysis indicated that the expression of $\beta$-catenin and its downstream target c-myc in the Wnt signaling pathway was downregulated in a resveratrol dose-dependent manner (Fig. 3). Furthermore, the expression of $\beta$-catenin and c-myc were increased with the combination of CHIR 99021 

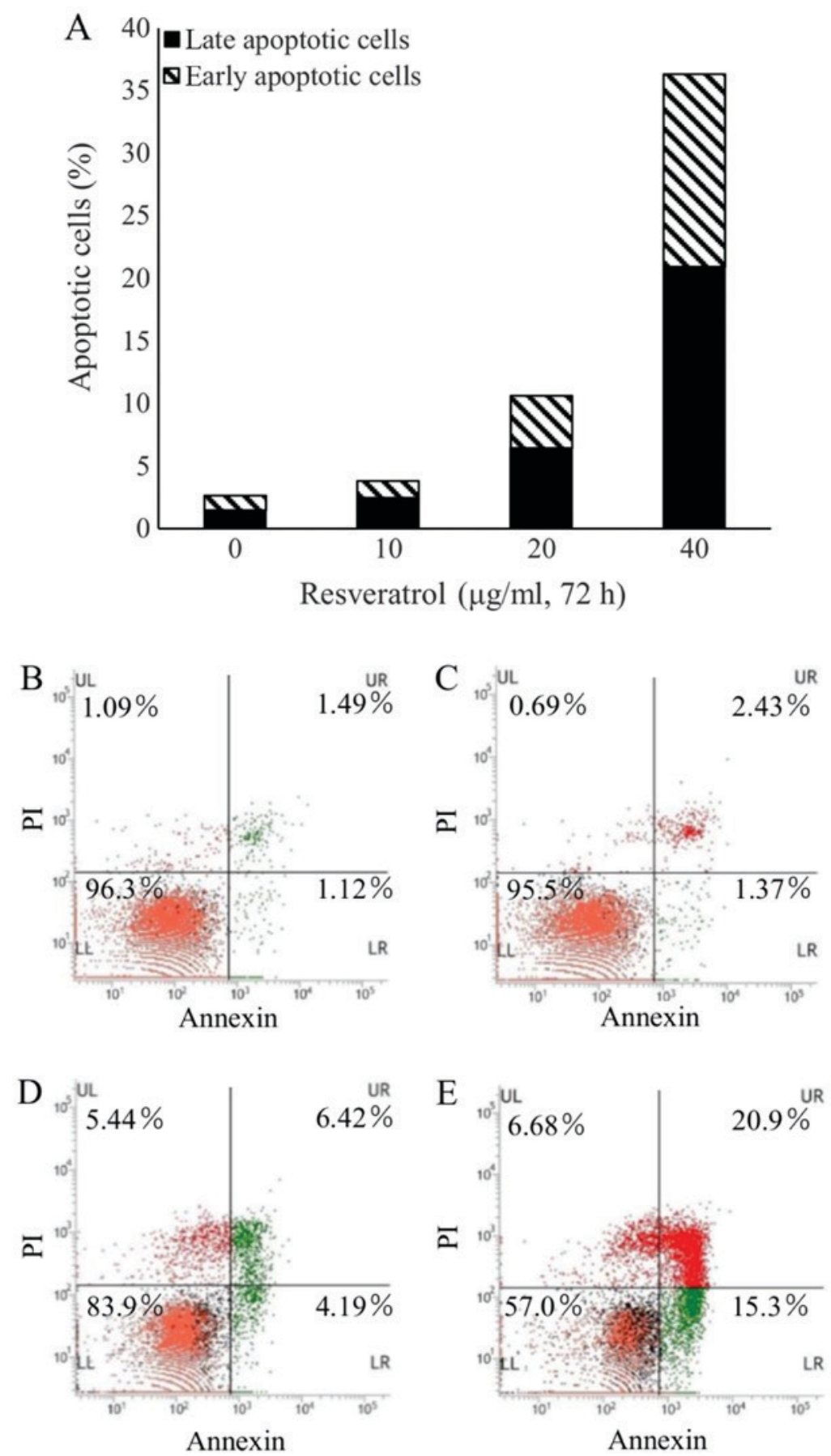

Figure 2. Effect of resveratrol on apoptosis in the human MES-SA uterus sarcoma cell line. Cells were treated with resveratrol for $72 \mathrm{~h}$, and apoptosis was determined by flow cytometry using an Annexin V kit. (A) Quantified amounts of cells in early and late apoptosis in groups treated with different concentrations of resveratrol. (B-E) Representative flow cytometry dot plots of MES-SA cells treated with resveratrol at (B) $0 \mu \mathrm{g} / \mathrm{ml}$, (C) $10 \mu \mathrm{g} / \mathrm{ml}$, (D) $20 \mu \mathrm{g} / \mathrm{ml}$ and (E) $40 \mu \mathrm{g} / \mathrm{ml}$. Quadrants: UL, necrotic cells; UR, late apoptotic cells; LL, live cells; LR, early apoptotic cells. PI, propidium iodide; UL, upper left; UR, upper right; LL, lower left; LR, lower right.

and resveratrol compared with the resveratrol alone group. CHIR99021 reduced the level of active $\beta$-catenin and c-myc by blunting the effect of resveratrol. This indicated that resveratrol inhibited upstream of GSK $3 \beta$ in the Wnt signaling pathway.

\section{Discussion}

The present results revealed that resveratrol inhibited the proliferation of cells and induced apoptosis in a dose-dependent manner. Although the effects of resveratrol were dependent on its dose, cytostatic effects were observed in uterine sarcoma cells following a prolonged exposure to a low dose. The expression of $\beta$-catenin in uterine sarcoma cells was detected by western blot analysis, revealing that its expression was inhibited by resveratrol in a dose-dependent manner. The expression of c-myc, the target gene of $\beta$-catenin, was similarly inhibited. GSK $3 \beta$ disintegrates as it phosphorylates $\beta$-catenin, thereby stabilizing $\beta$-catenin (12). When the phosphorylation of $\beta$-catenin is inhibited, accumulation of $\beta$-catenin activates the Wnt signaling pathway (13). The expression of $\beta$-catenin and suppression of 

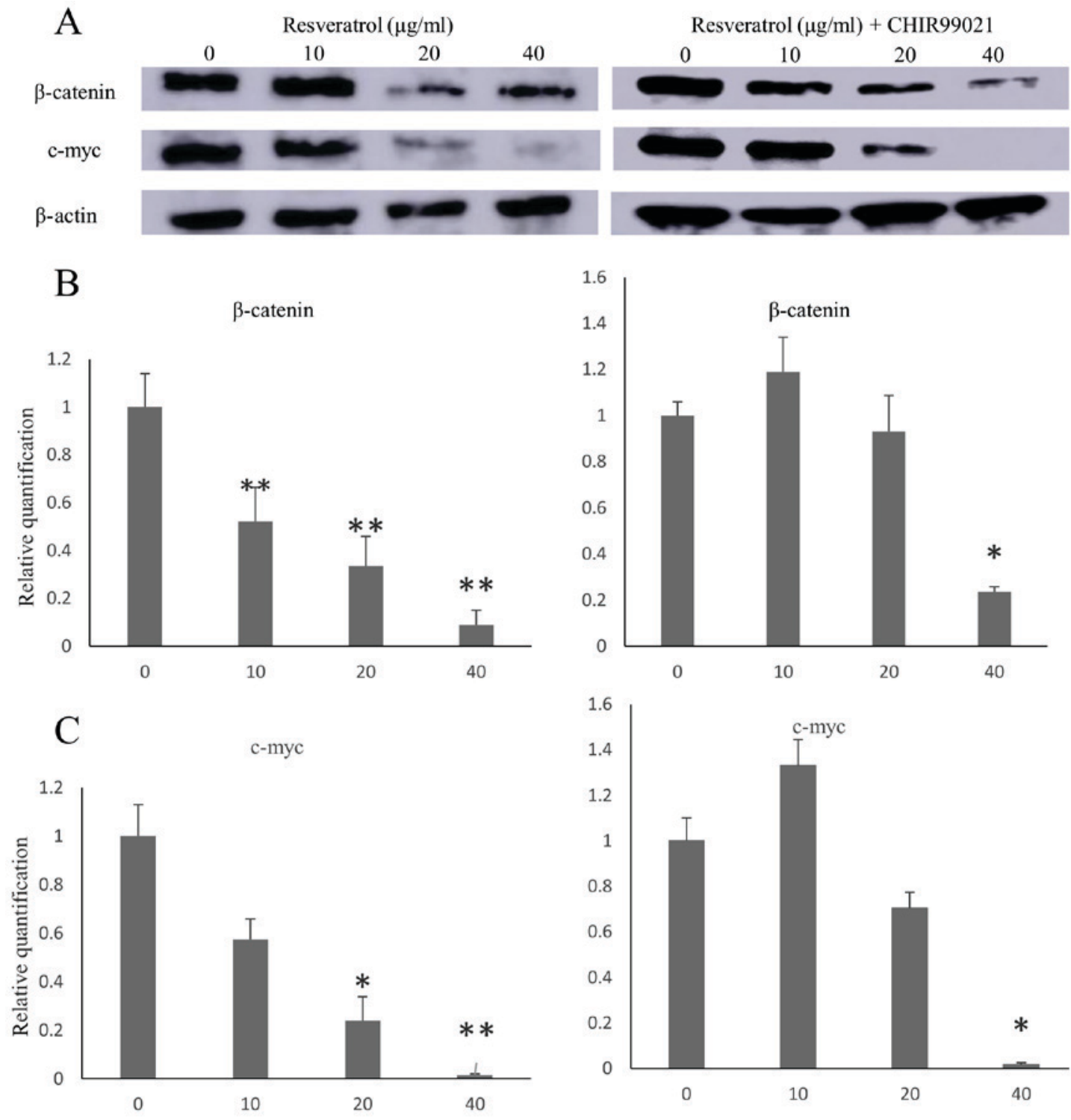

Resveratrol $(\mu \mathrm{g} / \mathrm{ml})$

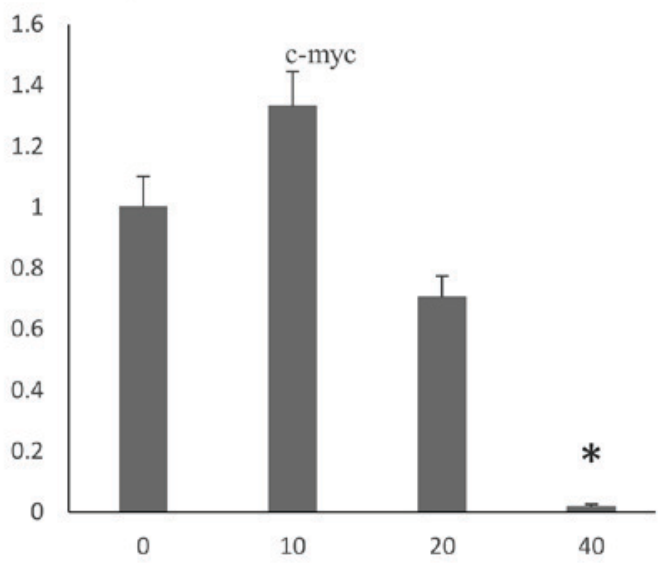

Resveratrol $(\mu \mathrm{g} / \mathrm{ml})+$ CHIR99021

Figure 3. $\beta$-Catenin and c-myc expression levels in the human MES-SA uterine sarcoma cell line following treatment with resveratrol for $48 \mathrm{~h}$. (A) Representative western blots for determining the expression of $\beta$-catenin and its target gene c-myc. (B and C) Quantified expression levels of $\beta$-catenin and c-myc (B) after resveratrol treatment at different concentrations and (C) after treatment with resveratrol vs. resveratrol and CHIR99021 (10 ng/ml). $\beta$-actin was used as the loading control. Values are expressed as the mean \pm standard error of the mean $(n=3)$. ${ }^{*} \mathrm{P}<0.05$ and ${ }^{* *} \mathrm{P}<0.01$ vs. the control.

c-myc were increased in cells treated with the combination of the GSK3 $\beta$ inhibitor and resveratrol. Resveratrol inhibits the proliferation of uterine sarcoma cells via the $\beta$-catenin/Wnt signaling pathway.

A previous study reported the activation of Wnt signaling in bone sarcoma cells (14). Resveratrol has been demonstrated to inhibit Wnt signaling in human osteosarcoma cells (15). After exposure to $40 \mu \mathrm{g} / \mathrm{ml}$ resveratrol for $72 \mathrm{~h}$, the apoptotic rates of osteosarcoma and uterine sarcoma were $27.5 \%$ (15). In colorectal cancer, resveratrol led to an apoptosis rate of $30 \%$ at $150 \mu \mathrm{M}$ (7). In the present study, an apoptotic rate of $43 \%$ was determined at the same concentration. The cytostatic effects of resveratrol were marked at $40 \mu \mathrm{g} / \mathrm{ml}$, and the expression of $\beta$-catenin and c-myc was not upregulated by the GSK $3 \beta$ inhibitor. The cytostatic effects of resveratrol at a lower concentration may be greater in uterine sarcoma cells than in osteosarcoma cell and colon cancer cell.

The Wnt/ $\beta$-catenin signaling pathway has an important role in normal developmental processes, and is activated in neoplastic cells (16). Thus, the inhibition of this signal may cause side effects due to stem cell dysfunction (11).

Antioxidant (17) and cranial nerve protective effects (18) have been reported at low doses of resveratrol, and preventive effects regarding colon cancer have been demonstrated (19). A previous study reported the absence of severe side effects in healthy human subjects administered $5 \mathrm{~g}$ resveratrol (20). Resveratrol may exert anti-tumor effects without any serious adverse effects by inhibiting the Wnt signaling pathway in a concentration-dependent manner.

One of the limitations of resveratrol is its low bioavailability (21). Previous studies reported on the effects of resveratrol 
on breast, liver, pancreas, prostate, and bladder cancer in vivo. In uterine sarcoma, the detailed mechanisms of action of resveratrol have remained elusive, and further in vivo research similar to that performed for other cancer types $(22,23)$ is required in order to elucidate the underlying mechanisms.

In conclusion, the present study demonstrated that resveratrol inhibited the proliferation of human MES-SA uterine sarcoma cells, possibly by downregulating the expression of $\beta$-catenin and c-myc in the Wnt signaling pathway. The present results indicate the potential of resveratrol as a novel treatment for uterine sarcoma.

\section{Acknowledgements}

For the present study, experimental equipment was provided by the Center for Advanced Medical Sciences, Institute of Biomedical Sciences, Tokushima University Graduate School (Tokushima, Japan).

\section{Funding}

This research did not receive any specific grant from any funding agencies of the public, commercial or not-for-profit sectors.

\section{Availability of data and materials}

The datasets generated and/or analysed during the current study are available from the corresponding author on reasonable request.

\section{Authors' contributions}

AM, ET and TaK analyzed and interpreted the data regarding the effect of resveratrol in uterine sarcoma. AM performed all experiments, and was a major contributor in writing the manuscript. MN, ToK, AA and MI were involved in writing and revising the manuscript. All authors read and approved the final manuscript.

\section{Ethical approval and consent to participate}

Not applicable.

\section{Patient consent for publication}

Not applicable.

\section{Competing interests}

All authors declare that they have no competing interests to disclose.

\section{References}

1. Tsukamoto T, Nakata R, Tamura E, Kosuge Y, Kariya A Katsukawa M, Mishima S, Ito T, Iinuma M, Akao Y, et al: Vaticanol $\mathrm{C}$, a resveratrol tetramer, activates PPARalpha and PPARbeta/delta in vitro and in vivo. Nutr Metab (Lond) 7: 46, 2010.

2. Jang M, Cai L, Udeani GO, Slowing KV, Thomas CF, Beecher CW, Fong HH, Farnsworth NR, Kinghorn AD, Mehta RG, et al: Cancer chemopreventive activity of resveratrol, a natural product derived from grapes. Science 275: 218-220, 1997.
3. Logan CY and Nusse R: The Wnt signaling pathway in development and disease. Annu Rev Cell Dev Biol 20: 781-810, 2004.

4. Kawakita T, Masato N, Takiguchi E, Abe A and Irahara M: Cytotoxic effects of 15-deoxy- $\Delta 12,14$-prostaglandin $\mathrm{J} 2$ alone and in combination with dasatinib against uterine sarcoma in vitro. Exp Ther Med 13: 2939-2945, 2017.

5. Dai H, Deng HB, Wang YH and Guo JJ: Resveratrol inhibits the growth of gastric cancer via the $\mathrm{Wnt} / \beta$-catenin pathway. Oncol Lett 16: 1579-1583, 2018.

6. Cilibrasi C, Riva G, Romano G, Cadamuro M, Bazzoni R, Butta V, Paoletta L, Dalprà L, Strazzabosco M, Lavitrano M, et al: Resveratrol impairs glioma stem cells proliferation and motility by modulating the Wnt signaling pathway. PLoS One 12: e0169854, 2017.

7. Vanamala J, Reddivari L, Radhakrishnan S and Tarver C: Resveratrol suppresses IGF-1 induced human colon cancer cell proliferation and elevates apoptosis via suppression of IGF-1R/Wnt and activation of p53 signaling pathways. BMC Cancer 10: 238 , 2010.

8. Hope C, Planutis K, Planutiene M, Moyer MP, Johal KS, Woo J, Santoso C, Hanson JA and Holcombe RF: Low concentrations of resveratrol inhibit Wnt signal throughput in colon-derived cells: Implications for colon cancer prevention. Mol Nutr Food Res 52 (Suppl 1): S52-S61, 2008.

9. Guastalla JP, Bachelot T and Ray-Coquard I: Cyclooxygenase 2 and breast cancer. From biological concepts to clinical trials. Bull Cancer 91 (Suppl 2): S99-S108, 2004 (In French).

10. Nguyen AV, Martinez M, Stamos MJ, Moyer MP, Planutis K, Hope $\mathrm{C}$ and Holcombe RF: Results of a phase I pilot clinical trial examining the effect of plant-derived resveratrol and grape powder on Wnt pathway target gene expression in colonic mucosa and colon cancer. Cancer Manag Res 3: 25-37, 2009.

11. Kahn M: Can we safely target the WNT pathway? Nat Rev Drug Discov 13: 513-532, 2014.

12. Kikuchi A: Tumor formation by genetic mutations in the components of the Wnt signaling pathway. Cancer Sci 94: 225-229, 2003.

13. Yost C, Torres M, Miller JR, Huang E, Kimelman D and Moon RT: The axis-inducing activity, stability, and subcellular distribution of beta-catenin is regulated in Xenopus embryos by glycogen synthase kinase 3. Genes Dev 15: 1443-1454, 1996.

14. Chen C, Zhao M, Tian A, Zhang X, Yao Z and Ma X: Aberrant activation of $\mathrm{Wnt} / \beta$-catenin signaling drives proliferation of bone sarcoma cells. Oncotarget 6: 17570-17583, 2015.

15. Zou Y, Yang $J$ and Jiang D: Resveratrol inhibits canonical Wnt signaling in human MG-63 osteosarcoma cells. Mol Med Rep 12: 7221-7226, 2015.

16. Barker $\mathrm{N}$ and Clevers $\mathrm{H}$ : Mining the Wnt pathway for cancer therapeutics. Nat Rev Drug Discov 5: 997-1014, 2006.

17. Frankel EN, Waterhouse AL and Kinsella JE: Inhibition of human LDL oxidation by resveratrol. Lancet 341: 1103-1104, 1993.

18. Mehlig K, Skoog I, Guo X, Schütze M, Gustafson D, Waern M, Ostling S, Björkelund C and Lissner L: Alcoholic beverages and incidence of dementia: 34-year follow-up of the prospective population study of women in Goteborg. Am J Epidemiol 15: 684-691, 2008.

19. Holcombe RF, Martinez M, Planutis K and Planutiene M: Effects of a grape-supplemented diet on proliferation and Wnt signaling in the colonic mucosa are greatest for those over age 50 and with high arginine consumption. Nutr J 14: 62, 2015.

20. Boocock DJ, Faust GE, Patel KR, Schinas AM, Brown VA, Ducharme MP, Booth TD, Crowell JA, Perloff M, Gescher AJ, et al: Phase I dose escalation pharmacokinetic study in healthy volunteers of resveratrol, a potential cancer chemopreventive agent. Cancer Epidemiol Biomarkers Prev 16: 1246-1252, 2007.

21. Yu C, Shin YG, Chow A, Li Y, Kosmeder JW, Lee YS, Hirschelman WH, Pezzuto JM, Mehta RG and van Breemen RB: Human, rat, and mouse metabolism of resveratrol. Pharm Res 19: 1907-1914, 2002.

22. Wu ML, Li H, Yu LJ, Chen XY, Kong QY, Song X, Shu XH and Liu J: Short-term resveratrol exposure causes in vitro and in vivo growth inhibition and apoptosis of bladder cancer cells. PLoS One 9: e89806, 2014.

23. Carter LG, D'Orazio JA and Pearson KJ: Resveratrol and cancer: Focus on in vivo evidence. Endocr Relat Cancer 21: R209-R225, 2014.

This work is licensed under a Creative Commons Attribution-NonCommercial-NoDerivatives 4.0 International (CC BY-NC-ND 4.0) License. 